\title{
Acute intoxication following massive bupropion sniffing: A case report
}

\author{
Simone Sartori, ${ }^{1}$ Valentina Brilli, ${ }^{1}$ Cecilia Lanzi, ${ }^{2}$ Luca Pratticò, ${ }^{3}$ Elisabetta Sarcoli, ${ }^{3}$ \\ Maria Grazia Di Milia, ${ }^{4}$ Francesco Gambassi, ${ }^{2}$ Guido Mannaioni ${ }^{1,2}$ \\ ${ }^{1}$ Department of Neurosciences, Psychology, Drug Research and Child Health, Section of Pharmacology and \\ Toxicology, University of Florence, Florence; ${ }^{2}$ Medical Toxicology Unit and Poison Control Centre, Careggi \\ University Hospital, Florence; ${ }^{3}$ Emergency Department, Azienda USL Toscana sud est, Grosseto; ${ }^{4}$ Forensic \\ Toxicology Unit, Medical Toxicology Unit and Poison Control Centre, Careggi University Hospital, \\ Florence, Italy
}

\begin{abstract}
Bupropion intranasal misuse potential should be considered in the suspect of sympathomimetic syndrome for illicit drug or medication intoxication. A 31-year-old man was admitted for intranasal misuse of 30 crushed tablets of bupropion with adrenergic mild presentation. Lorazepam infusion was started with complete clinical resolution. Further forensic investigations detected a bupropion serum and urine concentration levels at 18 hours from intake of
\end{abstract}

Correspondence: Simone Sartori, Medical Toxicology Unit and Poison Control Centre, Viale San Luca Vecchio, Careggi University Hospital, Florence, Italy.

Tel.: +39.055.7946244

E-mail: simone.sartori@unifi.it

Key words: Bupropion; abuse; sniffing; intoxication; case report.

Contribution: All Authors equally contributed in the development of this paper. SS, VB, LP, ES and MGDM collected data. SS and FG initiated the idea. SS performed a literature search and wrote the paper. VB helped with writing the paper. CL, FG and MG reviewed the manuscript. MG acts as the guarantor of the paper.

Conflict of interest: The authors declare no conflict of interests.

Availability of data and materials: All data underlying the findings are fully available from the corresponding author upon reasonable request.

Ethics approval and consent to participate: No ethical committee approval was required for this case report by the Department, because this article does not contain any clinical studies with human participants or animals.

Consent for publication: Not applicable. The evaluation of the case was performed using anonymized patient data, therefore without the need for patient consent.

Received for publication: 13 August 2021.

Revision received: 4 December 2021.

Accepted for publication: 6 December 2021.

This work is licensed under a Creative Commons Attribution 4.0 License (by-nc 4.0).

(C) Copyright: the Author(s), 2021

Licensee PAGEPress, Italy

Emergency Care Journal 2021; 17:10037

doi:10.4081/ecj.2021.10037
$1905.26 \mathrm{ng} / \mathrm{mL}$ and $2001.57 \mathrm{ng} / \mathrm{mL}$, respectively. This case of intranasal bupropion misuse shared only some features with oral overdose, despite a plasma concentration five times higher than the lowest toxic level. Nasal bupropion snorting in chronic users could have lower toxicity compared to other snorted stimulants but symptomatic treatment remains the gold standard for preventing complications. Bupropion misuse might rapidly become a concerning issue and monitoring by healthcare professionals is needed.

\section{Introduction}

Despite being an under-recognized phenomenon, prescription and Over The Counter (OTC) medication misuse (a practice known with the term "pharming") is rapidly becoming an issue of world-wide concern. ${ }^{1}$

Bupropion is an atypical antidepressant with medical indication for major or seasonal depressive disorder and smoking cessation, ${ }^{2}$ in addition to off-label uses for Attention Deficit Hyperactivity Disorder (ADHD), obesity, binge-eating disorder and some Substance Use Disorder (SUD) (e.g. cocaine and methamphetamine). ${ }^{3}$ Bupropion acts by blocking dopamine, norepinephrine and to a lesser extent serotonin reuptake. It also acts as an antagonist on many nicotine receptors. ${ }^{4}$ Its chemical structure is similar to cathinone, a natural stimulant extracted from Catha edulis, and therefore it is comprised within the pharmacological class of substituted cathinones along with other synthetic compounds (e.g. amphetamines and 'bath salts'). ${ }^{5}$ Bupropion has a narrow therapeutic window, leading to severe cases of overdose with possible fatal complication such as seizures ${ }^{6}$ and heart failure. ${ }^{7}$

Despite the belief of bupropion having a lesser addictive potential compared to cocaine or amphetamines, ${ }^{5}$ issues about its non-medical use have been raised for years ${ }^{1}$ especially among young adults ${ }^{8}$ and inmates in correctional facilities. ${ }^{9}$ Its recreational snorting misuse has been reported since $2002,{ }^{10}$ whereas overdose ingestion is more associated with suicidal attempts. ${ }^{11}$ Intravenous (IV) bupropion abuse has also been reported ${ }^{12}$ sometimes leading to serious complications. ${ }^{13}$

We hereby present a case of nasal sniffing of a huge amount of bupropion crushed tablets, requiring benzodiazepine (BZD) infusion without the development of any major complication.

\section{Case Report}

In April 2021, a 31-year-old man was referred to the Emergency Department 2 hours after sniffing 30 crushed bupropion tablets "for playful purpose".

His medical history was positive for ADHD treated with psy- 
chotherapy and bupropion (unknown formulation dosage) besides a previously diagnosed cocaine use disorder.

Mental confusion, hypertension, deep tendon hyperreflexia and dry mouth were present at medical examination while electrocardiogram (ECG) at arrival showed sinus tachycardia with a 484 msec corrected QT interval (QTc) prolongation (Figure 1). No QRS complex alteration was present. The above-mentioned findings were compatible with the suspected intoxication.

A toxicology consultation was requested and Poison Control Centre (PCC) suggested cardiac monitoring in addition to IV rehydration. Given the risk of hyper-activation status, possible seizures and serotonin syndrome due to the hypothetical high amount of absorbed bupropion, lorazepam (4 mg IV) was administered.

Subsequent electroencephalogram (EEG) and CT-scan ruled out any evidence of neurologic impairment (epileptic patterns, parenchymal lesions and blood extravasation) due to acute bupropion intoxication. A toxicological urine screening was performed with resulting positivity only for BZD, whereas only mild leukocytosis was detected at blood test $\left(15.23 \times 10^{3} / \mathrm{uL}\right.$ with normal range 3.5-9.5).

Clinical signs and symptoms of intoxication normalized after 27 hours of observation without any complication. The patient decided to self-discharge after a psychiatric consultation, being therefore referred to his psychotherapist. To certify the reported intake of bupropion, blood and urine samples were taken 18 hours after the event in order to perform a second-level investigation with gas chromatography-mass spectrometry (GC-MS). Bupropion serum and urine concentration levels were 1905.26 and $2001.57 \mathrm{ng} / \mathrm{mL}$, respectively (Figure 2).

Urine toxicological screening and clinical monitoring of vital signs throughout hospitalization are summarized in Table 1.

\section{Discussion}

This case of intranasal bupropion misuse shared only some of the most common clinical features of a classical bupropion ingestion overdose (considering comparable amounts of medication). ${ }^{14}$ Therapeutic daily doses for bupropion are usually up to 300 $\mathrm{mg} /$ day ${ }^{15}$ reaching peak concentration after 1.5 hours and 3-5 hours for immediate or modified-release formulations, respectively. ${ }^{16}$ Half-life is about 21 hours in chronic users and it can be even longer for the presence of active metabolites. ${ }^{14}$ Therapeutic window is considered between 5 to $100 \mathrm{ng} / \mathrm{mL} \cdot{ }^{17}$ Although our patient's bupropion dose formulation was unknown, only $150 \mathrm{mg}$ and $300 \mathrm{mg}$ modified/sustained formulations are available on the

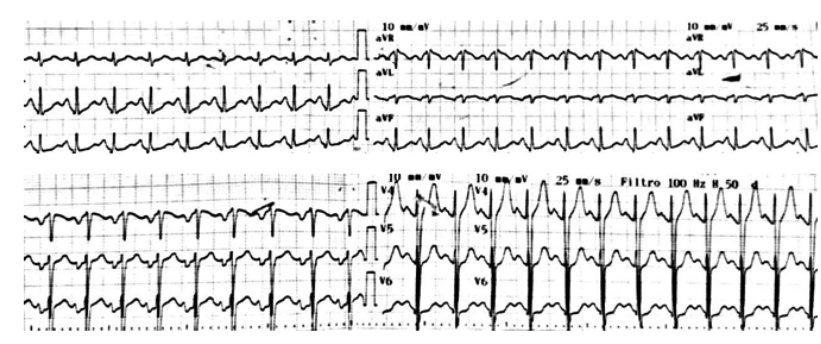

Figure 1. Sinus tachycardia with 125 beats per minute heart rate and nonspecific alterations of ventricular repolarization.QTc prolongation (484 $\mathrm{msec})$.

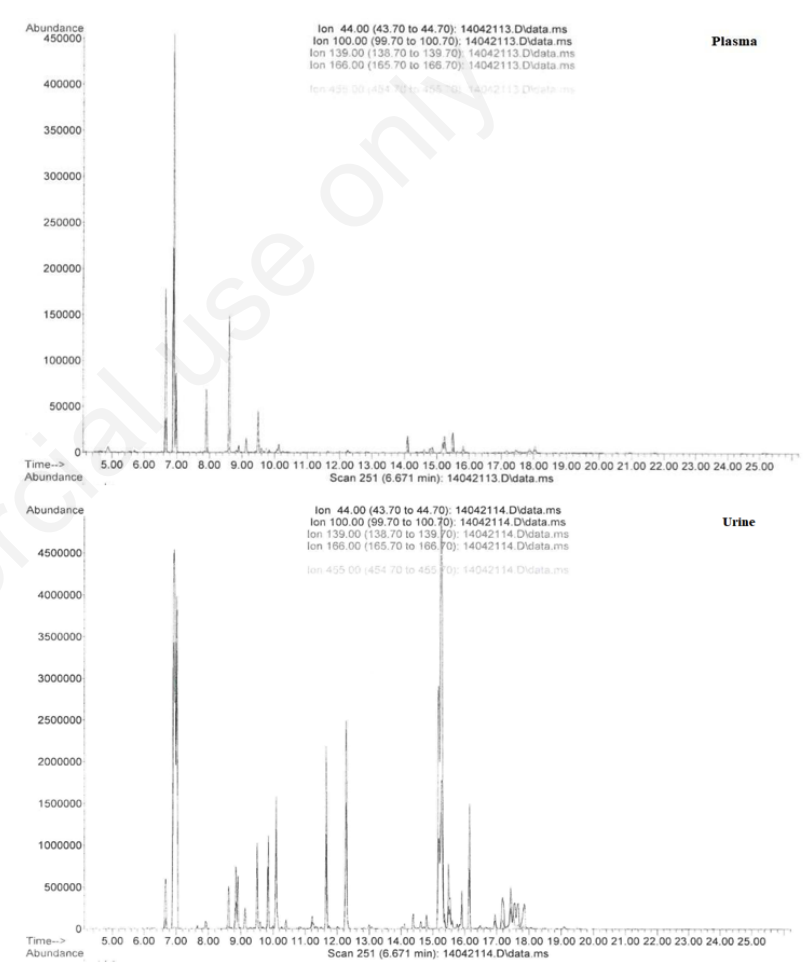

Figure 2. Bupropion serum and urine concentration levels at 18hours from the event.

Table 1. Patients vitals and laboratory screening during hospitalization.

\begin{tabular}{|c|c|c|c|c|c|c|c|}
\hline Vitals & Day 1 12:42 pm & Day $101: 41$ pm & Day 1 02:24 pm & Day 1 02:26 pm & Day 1 09:46 & pmDay 2 10:06 am & Day $214: 41$ pm \\
\hline $\mathrm{HR}(\mathrm{bpm})$ & 140 & & 88 & 120 & 95 & 90 & 85 \\
\hline RR & & & 20 & 16 & & & 16 \\
\hline BP (sys mmHg) & 158 & 130 & 133 & 133 & 122 & 120 & 130 \\
\hline $\mathrm{BP}$ (dia mmHg) & 116 & 60 & 72 & 72 & 82 & 70 & 79 \\
\hline $\mathrm{BT}\left(\mathrm{C}^{\circ}\right)$ & 36 & & 36 & 36.9 & 36 & 36 & 36.7 \\
\hline Pain (VAS) & & & & 1 & & & 0 \\
\hline GCS & & & 15 & 15 & 15 & 15 & 15 \\
\hline $\mathrm{SpO} 2(\% \mathrm{AA})$ & 97 & & 97 & 99 & 98 & 98 & 96 \\
\hline $\begin{array}{l}\text { Semi-quantitative } \\
\text { screening (urine) }\end{array}$ & Day 2 09:54 am & Amphetamine & Benzodiazepines+ & Cannabinoids & Cocaine & Methadone & Opioids \\
\hline
\end{tabular}


Italian market, making the possible total intranasal intake ranging from $4,5 \mathrm{~g}$ to $9 \mathrm{~g}$. Second-level forensic investigation assessed an 18-hour blood bupropion level of 1905,26 $\mathrm{ng} / \mathrm{ml}$, estimating this way an approximate $6 \mathrm{~g}$ intake consistent with the number of tablets stated by our patient (anecdotal computation given the different oral versus nasal route of administration).

Considering that decontamination would not be effective after intranasal misuse, this case suggests that this administration route might have less or slower absorption compared to an almost $100 \%$ absorption by enteral route ${ }^{4}$, differently from what happens with other typical snorted stimulants (e.g. cocaine) that have faster intranasal intoxication in contrast to its ingestion. ${ }^{18}$ Furthermore, neurologic complications are usually more likely above $450 \mathrm{mg}$ dosing. ${ }^{6}$ This case may imply that chronic abusers may not be as sensitive to average toxic levels as naïve or therapeutic use patients, as was also reported on a case of $2.1 \mathrm{~g}$ snorting without seizures occurrence. ${ }^{19}$ Another interesting aspect that could be considered is the different amount of active metabolites after nasal overdose compared to ingestion, due to lesser intestinal/hepatic metabolism. ${ }^{20}$ This could possibly explain a milder clinical presentation despite high dosages.

In spite of the known bupropion cross reactivity for amphetamines, ${ }^{21}$ only iatrogenic BZD were found in the patient's initial urine screening, requiring further investigations as to confirm the reported source of intoxication. High levels of the original compound were indeed assessed even after 18 hours from misuse. This stresses the idea that expectancy for urinary cross reactivity at standard screenings can underestimate the real incidence of bupropion abusers and it should be taken with a grain of salt.

As previously reported by other authors, ${ }^{22}$ leukocytosis can be found in case of oral bupropion overdose. Our case, despite the different route of exposition, was consistent with this aspect.

Eventually, in this case report we would like to underline the chance that bupropion nasal exposure toxicokinetic may differ from classical enteral intoxication. Still, symptomatic treatment of mild presentations with BZD remains the gold standard for preventing complications such as seizures and life-threatening arrhythmias.

Because of its "cathinone-like" properties, bupropion results among the most frequent antidepressants prone to pharming and this highlights the need for a more vigilant monitoring by healthcare professionals both in prescribing and selling medications, especially as long as specific categories are involved (e.g. unfamiliar patients or past SUD patients) and urine screenings may not always detect the misused substance. Prompt PCC consultation enables health providers to effectively manage intoxications deriving from unordinary administration routes for medication misuse.

\section{References}

1. Chiappini S, Schifano F. What about "Pharming"? Issues regarding the misuse of prescription and over-the-counter drugs. Brain Sci 2020;10:736.

2. Huecker MR, Smiley A, Saadabadi A. Bupropion. StatPearls 2021. Available from: https://www.ncbi.nlm.
nih.gov/books/NBK470212/

3. Trivedi MH, Walker R, Ling W, et al. Bupropion and naltrexone in methamphetamine use disorder. New Engl JMed 2021;384:140-53.

4. Costa R, Oliveira NG, Dinis-Oliveira RJ. Pharmacokinetic and pharmacodynamic of bupropion: integrative overview of relevant clinical and forensic aspects. Drug Metabolism Rev 2019;51:293-313.

5. Naglich AC, Brown ES, Adinoff B. Systematic review of preclinical, clinical, and post-marketing evidence of bupropion misuse potential. Am J Drug Alcohol Abuse. 2019;45:341-54.

6. Starr P, Klein-Schwartz W, Spiller H, et al. Incidence and onset of delayed seizures after overdoses of extended-release bupropion. Am JEmerg Med 2009;27:911-5.

7. Morazin F, Lumbroso A, Harry P, et al. Cardiogenic shock and status epilepticus after massive bupropion overdose. Clinical Toxicol 2007;45:794-7.

8. Stassinos GL, Klein-Schwartz W. Bupropion “abuse” reported to US Poison Centers. JAddict Med 2016;10:357-62.

9. Hilliard WT, Barloon L, Farley P, et al. Bupropion diversion and misuse in the correctional facility. JCorrect Health Care 2013;19:211-7.

10. Welsh CJ, Doyon S. Seizure induced by insufflation of bupropion. New Engl JMed 2002:347:951.

11. Sheridan DC, Lin A, Zane Horowitz B. Suicidal bupropion ingestions in adolescents: increased morbidity compared with other antidepressants. Clinical Toxicol 2018;56:360-4.

12. Baribeau D, Araki KF. Intravenous bupropion. JAddict Med 2013;7:216-7.

13. Strike M, Hatcher S. Bupropion injection resulting in tissue necrosis and psychosis. JAddict Med 2015;9:246-50.

14. Farkas J. Bupropion intoxication.Internet Book of Critical Care. 2019. Available from: https://emcrit.org/ibcc/bupropion

15. Norwegian Institute of Public Health. ATC/DDD Index. WHO Collaborating Centre for Drug Statistics Methodology. 2020.

16. Jefferson JW, Pradko JF, Muir KT. Bupropion for major depressive disorder: Pharmacokinetic and formulation considerations. Clinical Therapeutics. 2005;27:1685-95.

17. Preskorn SH. Antidepressant response and plasma concentrations of bupropion. JClinPsychiat 1983;44:137-9.

18. Nelson LS, Howland MA, Lewin NA, et al. Cocaine. Nelson L.S., \& Howland M, \&Lewin N.A., \& Smith S.W., \&Goldfrank L.R., \& Hoffman R.S.(Eds.), Goldfrank's Toxicologic Emergencies, 11e. McGraw Hill. Available from: https://accessemergencymedicine.mhmedical.com/content.asp $\mathrm{x}$ ?bookid $=2569$ \& sectionid $=210259752$

19. Yoon G, Westermeyer J. Intranasal bupropion abuse. Am JAddict 2013;22:180.

20. Costa R, Oliveira NG, Dinis-Oliveira RJ. Pharmacokinetic and pharmacodynamic of bupropion: integrative overview of relevant clinical and forensic aspects. Drug Metab Rev 2019;51:293-313.

21. Casey ER, Scott MG, Tang S, Mullins ME. Frequency of false positive amphetamine screens due to bupropion using theSyva Emit II Immunoassay. JMed Toxicol 2011;7:105-8.

22. Jolly TS, Singh J, Baweja R. Bupropion-Induced Severe Leukocytosis. Cureus 2020;12:e11083. 